\title{
Desenvolvimento e avaliação de descaroçador para o beneficiamento do algodão ${ }^{1}$
}

\author{
Francisco de A. C. Almeida², Maria E. R. Araújo 3 , 0 dilon R. R. F. da Silva ${ }^{4}$, \\ João F. dos Santos ${ }^{5} \&$ Josivanda P. G omes ${ }^{2}$
}

\begin{abstract}
RESUMO
Desenvolveu-se, através deste trabalho, um descaroçador de 20 serras, visando ao beneficiamento de al godão. As partes constituintes deste descaroçador consistem essencialmente, dos seguintes dispositivos: armação estática (chassi), constituída de duas chapas de ferro de espessura de 6,35 mm, para sustentação dos demais componentes da máquina; uma caixa acumuladora de algodão; câmara de descaroçamento de massa de algodão; dispositivo para regulagem da quantidade de línter; um cilindro composto de 20 serras e um outro de escovas; um condensador; alavanca de deslocamento e acionamento do cilindro descaroçador de discos; um motor elétrico trifásico de $5 \mathrm{CV}$, 320-220 V para acionamento dos dispositivos de beneficiamento por meio de polias e correias, e chave de partida automática. A avaliação do descaroçador se deu em comparação com as máquinas de 50 e 90 serras, amplamente utilizadas pelas usinas de beneficiamento de algodão no N ordeste brasileiro. 0 descaroçador desenvolvido responde satisfatoriamente ao beneficiamento do algodão e com desempenho similar ao das máquinas de 50 e 90 serras para todas as características tecnológicas analisadas da fibra no HVI. A melhor eficiência de trabalho do descaroçador de 20 serras foi para a rotação de $344 \mathrm{rpm}$, com o dispositivo para regulagem de quantidade de línter na posição $\mathrm{A}$ e amostra de $600 \mathrm{~g}$.
\end{abstract}

Palavras-chave: descaroçadores, desenvolvimento de máquinas, fibras de algodão

\section{Development and evaluation of coring machine for processing cotton seeds}

\begin{abstract}
In this study a ginner of 20 saws was developed for processing cotton seeds. The constituent parts of the ginner of 20 saws essentially consist of the following devices: static frame (chassis), consisting of tw o iron plates of $6.35 \mathrm{~mm}$ thickness, for the support of other components of the machine; a box of cotton accumulator; chamber of a mass of cotton ginning; device for regulating the amount of linter; a cylinder composed of 20 saws, another of brushes; a capacitor; gear for shifting and activating the cylinder, ginner discs; a three-phase $5 \mathrm{HP}$ electric motor, 320-220 V to drive the devices for processing, by means of pulleys and belts, and automatic switch. The evaluation of the 20 delinter saws was done in assessment with 50 and 90 saws machines widely used by the cotton benefiting factories in Northeast Brazil. The ginner developed responds satisfactorily to treatment of cotton seeds with performance similar to the machines of 50 and 90 saws for all technological fiber characteristics analyzed in HVI. The efficiency of the work of ginner was at $344 \mathrm{rpm}$, with the device to adjust the amount of linter in position A and the sample of $600 \mathrm{~g}$.
\end{abstract}

Key words: delintering, machinery developing, cotton fibers

\footnotetext{
1 Parte da Tese de Doutorado do segundo autor do Curso de Pós-Graduação em Agronomia CCA/U FPB

2 UAEA/U FCG, Av. A prígio Veloso, 882. CEP 58429-140. Fone: (83) 3310-1550. E-mail: almeida@deag.ufcg.edu.br; josi@deag.ufcg.edu.br

3 Doutora em Agronomia pelo CCA/UFPB. E-mail: elessandra@yahoo.com.br

${ }^{4}$ Pesquisador da Embrapa Algodão. Fone: (83) 3182-4300

${ }^{5}$ Pesquisador da Empresa Estadual de Pesquisa Agropecuária da Paraíba S/A. Fone: (83) 2101-1550. E-mail: joao_felinto_santos@hotmail.com
} 


\section{INTRODUÇÃO}

O beneficiamento do algodãoé a etapa inicial para a operação que visa á industrialização têxtil e consiste na separação da fibra das sementes através de processos mecânicos, buscandose manter as características intrínsecas da fibra e conferir, ao algodão, boa qualidade comercial; contudo, a falta de cuidados no manejo da lavoura, no processo de colheita e no manejo do algodão até a algodoeira, pode comprometer o produto, com impurezas diversas e indesejáveis pela indústria têxtil, de forma que a remoção desses contaminantes dificulta e onera significativamente o beneficiamento refletindo-se, muitas vezes, em deságio no preço final do fardo (Silva et al., 2010). Paiva et al. (2000) consideram que a intensidade e a gravidade dos danos mecânicos causados às sementes na operação de beneficiamento, dependem do tipo de equipamentos utilizados cujas sementes, impactadas com velocidades mais elevadas, apresentaram os piores resultados de integridade física. No beneficiamento do algodão o grande desafio é minimizar os problemas ocorridos durante esta etapa que tem, como consequência, as perdas e os danos nas sementes. Jerônimo et al. (2006), argumenta que sementes de algodão severamente danificadas durante a colheita e o beneficiamento, sofrem reduções em sua qualidade fisiológica, passíveis de serem detectadas pelos testes de vigor e germinação. Para Souza et al. (2009), quando colhidas mecanicamente as sementes vêm do campo com considerável percentual de dano mecânico, que se estendem durante os processos de beneficiamento, causando altos índices de perda de qualidade.

O processo de beneficiamento do algodão é realizado por usinas que, na sua grande maioria, utilizam descaroçadores dotados de 80 até 198 serras cujo diâmetro pode ser de 11 3/4", 12 ", 16"e 18" e trabalham a uma rotação entre 500 a 750 rpm (Holt \& Laird, 2008). Essas usinas necessitam de uma série de equipamentos para beneficiarem o algodão, antes e após o descaroçamento nas operações de pré-limpeza, secagem ou umidificação e limpeza da fibra, por que se constituem em um empreendimento de custo muito elevado e requerem grandes volumes de algodão, restringindo o uso dessa tecnologia a pequenos produtores, de forma especial, que integram a agricultura familiar (Silva et al., 2002). Patil \& Patil (2010) desenvolveram uma máquina de rolo melhorada e estudou-se o seu desempenho verificando-se que essa pode ser usada para o descaroçamento do algodão com a permanência das características físicas.

A Embrapa Algodão e parceiros, visando oferecer uma alternativa de verticalização da produção através do beneficiamento do algodão, desenvolveram a miniusina de 50 serras com prensa enfardadeira, para associações ou cooperativas de pequenos produtores cujos resultados de agregação de valor à produção alcançam valores da ordem de 118\% (Silva, 2007).

A miniusina requer, além de ser estacionária, uma área de plantio de no mínimo 350 ha, chegando a até 700 ha de algodão e carece do deslocamento da produção até a unidade de beneficiamento, requerendo a infraestrutura de galpão, energia e de logística, cujo custo é bastante considerável além de se tratar de um investimento de capital elevado, em torno de cem mil reais, tornando este modelo inadequado para determinados tipos e tamanho de associação ou cooperativas (Silva, 2007).

Desta forma, faz-se necessário o desenvolvimento de uma descaroçadora de pequeno porte e móvel, para atender aos pequenos cotonicultores, sobretudo aos inseridos nos programas de agricultura familiar promovidos pelo governo brasileiro, como forma de sustentar e promover a retomada desta cultura no Nordeste do Brasil, cuja expansão do cultivo do algodão ficou limitada pela carência de máquina de beneficiamento, especialmente ao alcance do pequeno produtor.

A qualidade do trabalho de uma máquina descaroçadora de algodão depende de uma operação correta, das características do equipamento e do próprio destino do produto e não se pode deixar de considerar os efeitos diferenciados, como descaroçamento e deslintamento (Koç \& Demiryürek, 2005; Holt \& Laird; 2008; 2010).

As primeiras tentativas para separar a fibra da semente foram realizadas manualmente; mais tarde, surgiram na Índia, máquinas pequenas, muito simples, denominadas "churka", que podem ser consideradas precursoras dos descaroçadores de rolo. A partir deste modelo, o americano Jones McCarty desenvolveu, em 1740, o descaroçador de rolo, que revolucionou a prática do beneficiamento do algodão e cujo modelo e princípios de funcionamento deram origem aos modernos descaroçadores da atualidade, que hoje são utilizados para o beneficiamento de algodão de fibra longa e extra-longa ou em operações de caráter experimental. A técnica de extração consiste em submeter o algodão em caroço ao contato de um rolo de cobertura áspera (couro) que, auxiliado por duas navalhas, uma fixa e outra móvel, retira a fibra das sementes; este processo preserva as propriedades intrínsecas da fibra porém apresenta limitações em relação à capacidade de beneficiamento por unidade de tempo (Moore, 1977).

Em 1792 o americano Eli Whitney desenvolveu um descaroçador de serras; o órgão principal desta máquina era um cilindro de madeira ao qual estavam inseridos ganchos de ferro para extrair a fibra das sementes, auxiliado por outro cilindro de escovas, para completar a operação. Em 1976, outro americano, Henry Ogden Holmes, inventou o descaroçador de serras porém com costelas. Essas invenções foram o início da indústria de máquinas para beneficiamento do algodão (Holt \& Laird, 2008; 2010).

Os descaroçadores de serra modernos são de uso universal e se destinam ao beneficiamento de algodão de fibra média e curta, funcionam através de serras circulares com dentes de passo, formato e inclinação especial, que giram por entre as costelas; o processo de extração ocorre quando a fibra engancha nos dentes das serras e é arrastada por entre as costelas para uma outra posição, quando então é retirada, através de operações mecânicas ou pneumáticas (Moore, 1977; Mangialardi Júnior \& Anthony, 1998). Esses equipamentos apresentam grande capacidade operacional, necessitam de ajustes regulagens especiais e de cuidados permanentes. Esta operação poderá influenciar significativamente as características intrínsecas e extrínsecas da fibra, que interferem na fabricação e na qualidade do fio e, consequentemente, na tecelagem e no processo de tinturaria em que o processo de 
beneficiamento do algodão poderá ter efeito significativo em várias características da fibra, como comprimento médio, uniformidade de comprimento, impurezas, neps e grau de cor, os quais interferem nos processos têxteis e na qualidade do fio, tecido e malha.

A região Nordeste, em particular os estados da Paraíba, Ceará, Rio Grande do Norte e Bahia, pretende estimular a cotonicultura incorporando, também, sistemas de produção e tecnologia voltados para o pequeno produtor, tornando-o um competitivo cotonicultor de fibras, como é o caso da Paraíba, que já trabalha com a agricultura familiar.

Esta iniciativa exige, dentro da cadeia têxtil, mudanças, visando à participação do pequeno produtor nesses novos tempos. Para que este cenário se modifique é necessário que esses produtores sejam contemplados com inovações tecnológicas, como uma descaroçadora de pequeno porte e móvel, tecnicamente tão eficiente quanto as existentes no mercado e lhes possam ser acessíveis e forneçam igual qualidade da fibra quanto às características tecnológicas, tal como as físicas e fisiológicas da semente sendo, no momento, o reclame maior dos pequenos cotonicultores que desejam vislumbrar um novo perfil da cotonicultura nacional e que a ela almejam inserir-se.

Face ao exposto objetivou-se, com este trabalho, desenvolver e avaliar um descaroçador de 20 serras para o beneficiamento do algodão.

\section{MATERIAL E MÉTODOS}

O presente trabalho foi realizado no Laboratório de Armazenamento e Pré-Processamento de Produtos Agrícolas (LAPPA) da unidade acadêmica de Engenharia Agrícola da Universidade Federal de Campina Grande (UFCG), em conjunto com os laboratórios de Fibra e de Sementes da Embrapa Algodão, em Campina Grande, Paraíba.

\section{Concepção e construção do descaroçador de 20 serras}

As partes constituintes do descaroçador de 20 serras se encontram no desenho esquemático na Figura 1, as quais consistem, essencialmente, dos seguintes dispositivos: armação estática (chassi), constituída de duas chapas de ferro de espessura $6,35 \mathrm{~mm}$, para sustentação dos demais componentes da máquina; uma caixa acumuladora de algodão; câmara de descaroçamento de massa de algodão; dispositivo para regulagem da quantidade de línter; um cilindro de 20 serras e outro de escovas; um condensador; alavanca de deslocamento e acionamento do cilindro descaroçador de discos; um motor elétrico trifásico de $5 \mathrm{CV}, 320-220 \mathrm{~V}$ para acionamento dos dispositivos de beneficiamento, por meio de polias e correias e chave de partida automática.

\section{Caracterização do descaroçador de 20 serras}

Realizaram-se, para avaliação do desempenho do descaroçador de 20 serras, testes com o intuito de se estabelecer a velocidade de trabalho em função das polias e ajustar o posicionamento do dispositivo para regulagem da quantidade de línter, variando ao posicionamento e ao tamanho da amostra

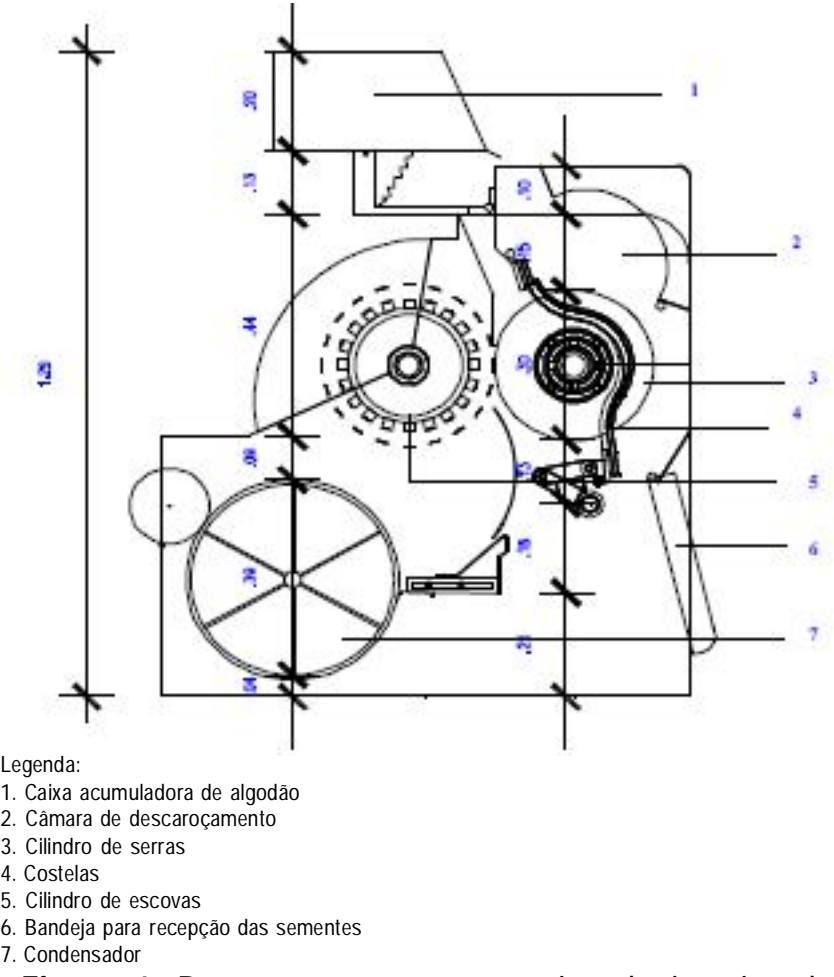

Figura 1. Representação esquemática do interior do descaroçador de 20 serras em escala reduzida

que alimenta a máquina. O condensador é um cilindro construído de tela de arame galvanizado, com diâmetro de $380 \mathrm{~mm}$ e baixa rotação, que atua como aglutinador da pluma (Figura 2).
A.

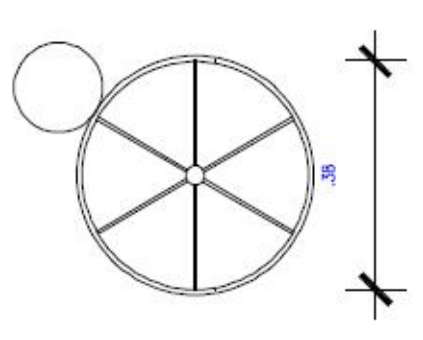

C.
B.

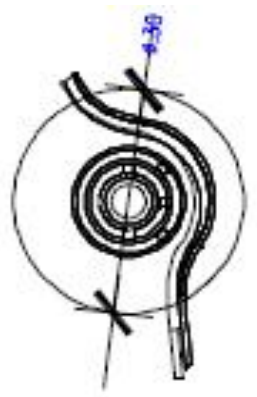

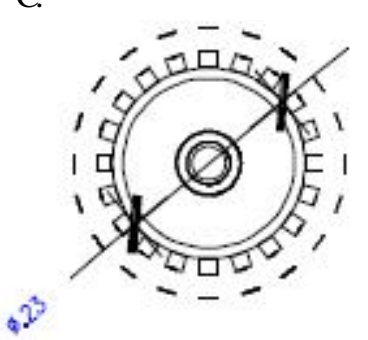

Figura 2. Representação esquemática do conjunto condensador $(A)$ de cilindro de serras e costelas $(B)$ e cilindro de escovas (C)

A rotação das serras foi alterada mediante a substituição da polia do motor que aciona o descaroçador de 20 serras, utilizando-se as polias de 70, 80 e $100 \mathrm{~mm}$ de diâmetro para obtenção das rotações de 304, 344 e 429 rpm, respectivamente. 
As velocidades medidas nas polias dos descaroçadores foram determinadas em um tacômetro modelo Venture, com leitura máxima de $50.000 \mathrm{rpm}$. Obtiveram-se as diferentes quantidades de algodão utilizadas na câmara de descaroçamento (300, 600, $900,1100 \mathrm{~g}$ ) por determinação de sua massa, em balança analítica de precisão. Visando ao dispositivo de regulagem da quantidade de línter (aberturas) testaram-se três posicionamentos (Figura 2A, 2B e 2C); depois da separação da semente das fibras, estas foram submetidas a avaliações quanto às características tecnológicas da fibra e às físicas e fisiológicas da semente.

\section{Avaliação do descaroçador de 20 serras frente a usinas con- vencionais}

A avaliação do descaroçador de 20 serras ocorreu mediante a análise estatística das análises individuais das características tecnológicas das fibras realizadas em cada máquina (usinas e descaroçador de 20 serras). As quantidades de algodão em rama utilizadas nas máquinas de 90 e 50 serras foram de $60 \mathrm{~kg}$, em quatro repetições de $15 \mathrm{~kg}$ e as utilizadas no descaroçador de 20 serras foram $0,6 \mathrm{~kg}$ por repetição, totalizando $2,4 \mathrm{~kg}$, que correspondem ao melhor desempenho, trabalhando com 344 rpm e posicionamento do dispositivo para regulagem da quantidade de línter na posição"A”.

No Laboratório de Fibras da Embrapa Algodão, climatizado de acordo com as normas NBR 8428-84, ISO 139, ASTM D 1776-90, as amostras permaneceram a uma temperatura de $20 \pm$ $1{ }^{\circ} \mathrm{C}$ e umidade relativa do ar de $65 \pm 2 \%$, durante $24 \mathrm{~h}$, antes de serem submetidas a análise.

Na calibragem se usaram os padrões especiais de calibragem: Calibration Cotton - HVI da USDA e ICC e na classificação comercial, os padrões físicos para algodões em pluma no Brasil, 1999/2000, aprovados pelo Ministério da Agricultura e do Abastecimento, como descritos a seguir:

\section{Finura da fibra}

Representa a resistência da fibra à passagem de ar em um chumaço de algodão sob condições prescritas nas normas NBR 11913-91 e ASTM D 1448-90, medida no HVI. O resultado na escala micronaire foi indicado em microgramas por polegada ao quadrado, e as médias obtidas comparadas com os padrões estabelecidos pela ASTM D 1448-90 (Tabela 1).

Tabela 1. Categoria de finuras das fibras

\begin{tabular}{lc}
\hline \multicolumn{1}{c}{ Categoria } & Micronaire $\left(\boldsymbol{\mu} \mathbf{~ p o l}^{-2}\right)$ \\
Muito fina & $<$ de 3,0 \\
Fina & 3,0 a 3,9 \\
Média & 4,0 a 4,9 \\
Grossa & 5,0 a 5,9 \\
Muito grossa & $>$ de 5,9 \\
\hline
\end{tabular}

Comprimento (mm) e uniformidade de comprimento $(\%)$

O comprimento obtido no HVI representa a média da metade superior das fibras (UHM - Upper Half Mean), distribuídas ao acaso em um pente ou pinça especial e medidas em milímetros; a uniformidade pela distribuição dos comprimentos é dada pela fórmula: ML(Mean Length)/UHM x 100 = UI\% (Tabela 2).
Tabela 2. Comprimento médio do algodão para sua classificação em categoria

\begin{tabular}{lcc}
\hline \multirow{2}{*}{ Categoria } & \multicolumn{2}{c}{ Comprimento de fibra } \\
\cline { 2 - 3 } Curta & SL $\mathbf{2 , 5 \%}$ & Comercial (mm) \\
Curta & Abaixo de 28,3 & Abaixo de 28 \\
Longa & 24,6 a 26,5 & 28 a 30 \\
Longa & 28,6 a 30,2 & 32 a 34 \\
Média & 30,9 a 31,7 & 34 a 36 \\
Muito longa & 27,0 a 27,8 & 30 a 32 \\
\hline
\end{tabular}

Índice de fibras curtas (\%) e índice de fiabilidade (\%)

São informados no HVI, pela proporção em percentagem de Fibras Curtas pelo Peso (w) com comprimento inferior a 12,7 mm existente na amostra de algodão, e o de fiabilidade pela relação de uniformidade das fibras obtida através da fórmula: UR\% $=50 \% / 2,5 \%$ X 100, em que UR é a taxa de uniformidade. As médias foram obtidas comparando-se os padrões contidos na ASTMD 1448-90 (Tabela 3).

Tabela 3. Tabela das categorias, quanto à uniformidade

\begin{tabular}{lcc}
\multicolumn{1}{c}{ Categoria } & Índice de uniformidade & Relação de uniformidade \\
Muito irregular & UI (\%) & UR (\%) \\
Irregular & $<$ de 77 & $<$ de 41 \\
Média & 77 a 79 & 41 a 42 \\
Uniforme & 80 a 82 & 43 a 44 \\
Muito uniforme & 83 a 85 & 45 a 46 \\
& $>$ de 85 & $>$ de 46 \\
\hline
\end{tabular}

\section{Resistência (gf/tex)}

Esta resistência foi medida no HVI pela tenacidade das fibras de algodão dispostas paralelamente em um feixe laminar de fibras que, em grama, representa a resistência da fibra requerida para romper um feixe de fibras em tex equivalente à massa, em gramas de $1000 \mathrm{~m}$ de fibra. A Tabela 4 foi utilizada para se conhecer as categorias quanto à resistência a tração do feixe de fibras plano.

Tabela 4. Categorias de resistência

\begin{tabular}{lc}
\hline \multicolumn{1}{c}{ Categoria } & Resistência (cN/tex) \\
Muito fraca & $<$ de 16,70 \\
Fraca & 16,71 a 21,50 \\
Média & 21,51 a 25,40 \\
Forte & 25,41 a 29,40 \\
Muito Forte & $>$ de 29,41 \\
\hline Fator de conversão para gf/tex $=\mathrm{cN} /$ tex $\times 1,019$ &
\end{tabular}

\section{Alongamento (\%)}

No sistema HVI as fibras são estiradas até o ponto de rompimento, o que permite registrar a curva de carga do alongamento, que é determinado a partir de $3,175 \mathrm{~mm}$ de comprimento, significando que $3,175 \mathrm{~mm}$ correspondem a $100 \%$ e um alongamento de $1 \%$ se refere ao alongamento das fibras, de $0,032 \mathrm{~mm}$.

\section{Reflectância (\% Rd)}

O valor de reflexão Rd, \%, obtido no HVI teve, como base, o conteúdo de cinza existente na amostra de algodão e corresponde à reflexão Rd \% da luz refletida pela amostra. 


\section{Grau de amarelecimento $(+b)$}

O grau de amarelecimento da amostra de algodão obtido no HVI, foi determinado com a ajuda de um filtro amarelo, indicado no diagrama de cor; a intersecção das coordenadas $\mathrm{Rd} \%$ e $+b$, indica o grau da cor.

\section{RESULTADOS E DISCUSSÃO}

Sequência das etapas de desenvolvimento do descaroçador de 20 serras

O descaroçador de 20 serras é uma máquina de concepção moderna, de simplicidade incomum e poucas regulagens, as quais dependem, em parte, da habilidade de manejo do operador, a fim de se obter uma separação precisa das fibras, preservando suas qualidades (Figura 3).

A.

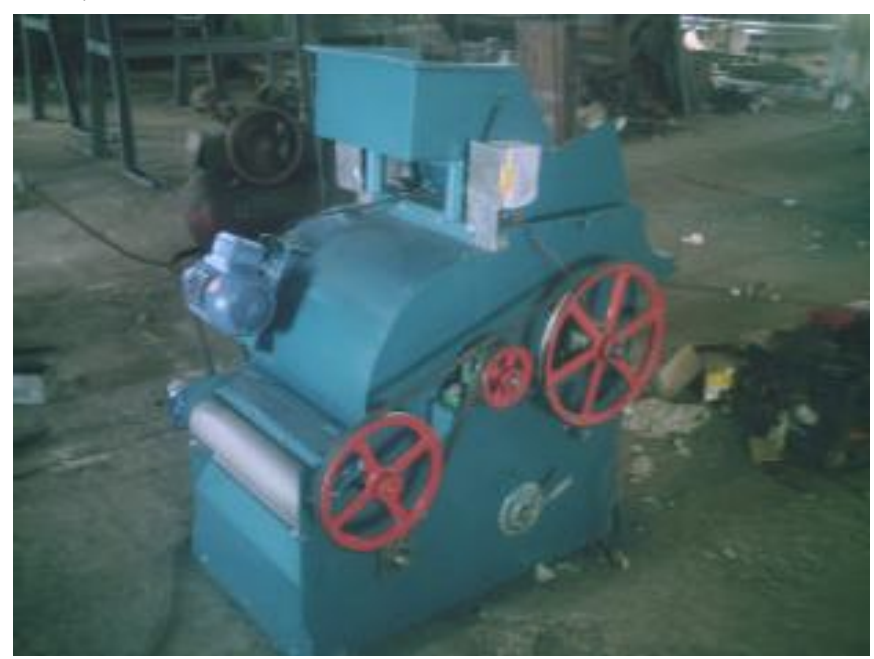

B.

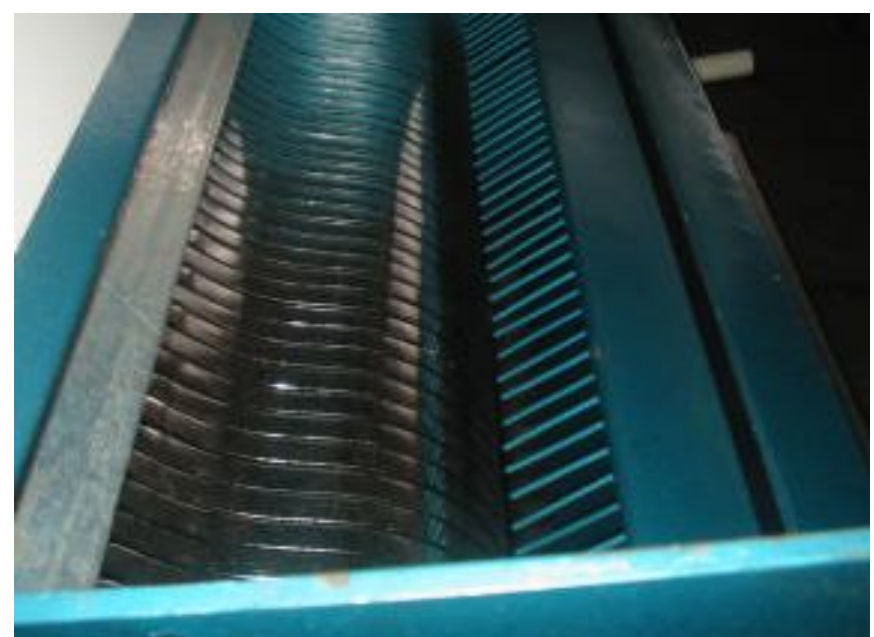

Figura 3. Foto do descaroçador de 20 serras (A) com detalhe do dispositivo para regulagem da quantidade de línter (B)

O sistema de descaroçamento ficou constituído de uma caixa acumuladora e câmara de descaroçamento com capacidade armazenadora de 3,5 e 2,5 kg, respectivamente; cilindro de serras de 300 mm de diâmetro, contendo 20 serras dentadas de 495,30 $\mathrm{mm}$ e costelas (Figura 4A); dispositivo para regulagem da quantidade de línter, constituído de uma grade de pinos, para aumentar ou diminuir a área de contato das serras com a massa de algodão seguindo-se, basicamente, os princípios de Moore (1977) e Mangialardi Júnior \& Anthony (1998).

Na Figura 4B se encontram a representação esquemática e a foto do cilindro de escovas de $230 \mathrm{~mm}$, desenvolvidas para o descaroçador de 20 serras, o qual atua junto aos dentes das serras, em sentido inverso ao da rotação e com velocidade bem superior à do cilindro de serras, com a finalidade de retirar a pluma contida nos dentes e impulsioná-la para o condensador.

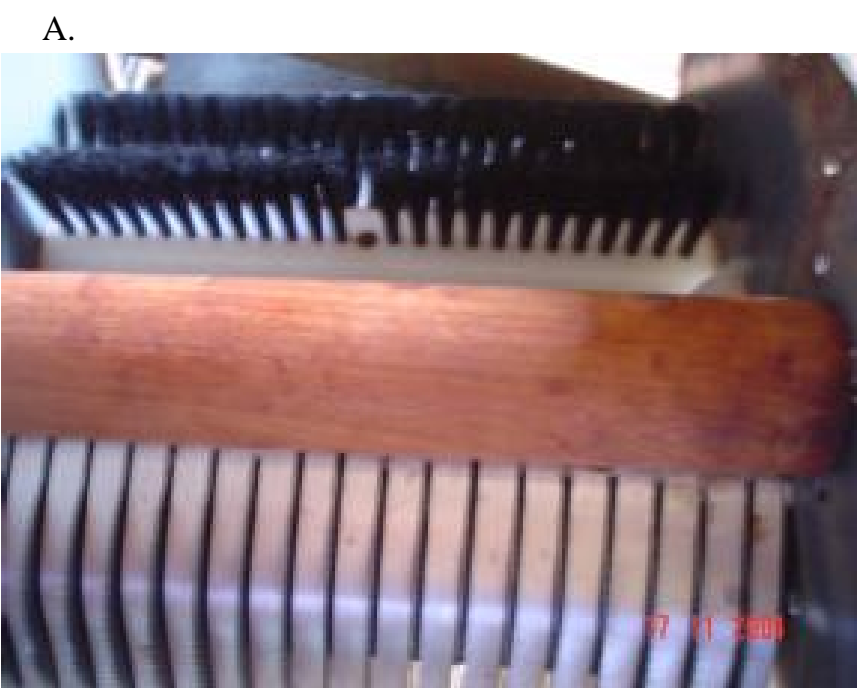

B.

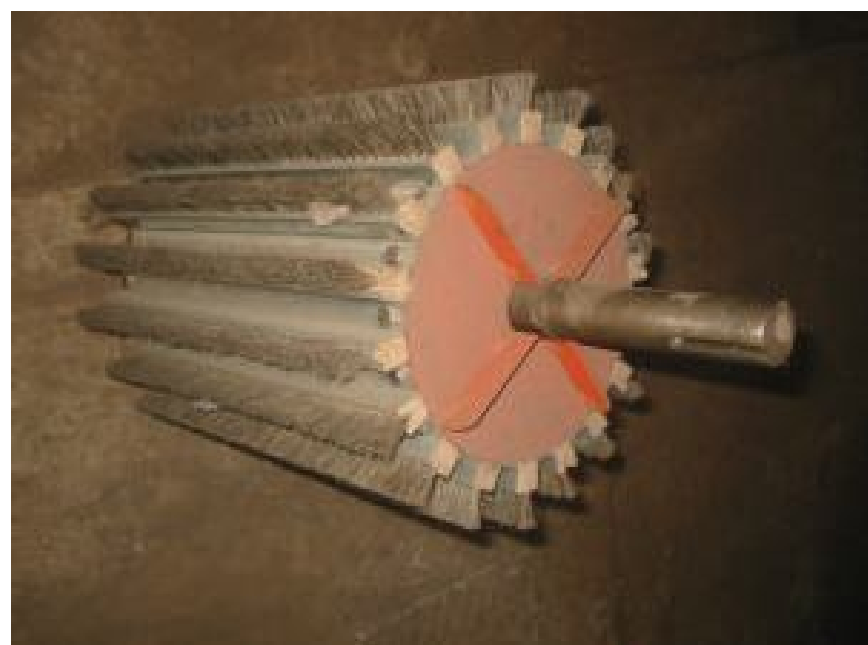

Figura 4. Foto do conjunto de cilindro de serras e costelas (A) e do cilindro de escovas (B)

Sequência das etapas de funcionamento do descaroçador de 20 serras

O abastecimento do descaroçador de 20 serras é feito manualmente, colocando-se algodão em rama na caixa acumuladora (Figura 5A), localizada na sua parte superior; em seguida, o algodão passa para a câmara de descaroçamento (Figura 5B); depois, aciona-se o motor para movimentar todos os dispositivos da máquina; logo após este procedimento movimenta-se lentamente a alavanca de deslocamento do cilindro descaroçador de 20 serras (Figura 5D), para que elas penetrem na 
Tabela 5. Resumo da análise de variância das características tecnológicas da fibra beneficiada no descaroçador de 20 serras. Campina Grande, PB, 2007

\begin{tabular}{|c|c|c|c|c|c|c|c|c|c|}
\hline \multirow{2}{*}{ F. V. } & \multirow{2}{*}{ GL } & \multicolumn{8}{|c|}{ Variáveis } \\
\hline & & MIC & STR & COMP & UNIF & IFC & ELON & CSP & $+b$ \\
\hline Rotação (R) & 2 & $6,15^{* *}$ & $7,25 * *$ & $1,34 \mathrm{~ns}$ & $3,22 *$ & 3,01 ns & $0,06 \mathrm{~ns}$ & $2,03 \mathrm{~ns}$ & $3,40 *$ \\
\hline $\mathrm{T}$, amostra $(\mathrm{T})$ & 3 & 28,40 ** & $1,78 \mathrm{~ns}$ & $15,9 * *$ & $0,33 \mathrm{~ns}$ & $1,58 \mathrm{~ns}$ & $4,31 * *$ & $3,14^{*}$ & $3,33 *$ \\
\hline PDRL (P) & 2 & $1,04 \mathrm{~ns}$ & $0,13 \mathrm{~ns}$ & $1,04 \mathrm{~ns}$ & $0,12 \mathrm{~ns}$ & $0,39 \mathrm{~ns}$ & $0,38 \mathrm{~ns}$ & $0,48 \mathrm{~ns}$ & $0,24 \mathrm{~ns}$ \\
\hline RXT & 6 & $2,18 \mathrm{~ns}$ & $1,26 \mathrm{~ns}$ & $3,34 * *$ & $1,21 \mathrm{~ns}$ & $1,64 \mathrm{~ns}$ & $1,88 \mathrm{~ns}$ & $1,15 \mathrm{~ns}$ & $6,36 * *$ \\
\hline RxP & 4 & $2,68 *$ & $1,55 \mathrm{~ns}$ & $0,77 \mathrm{~ns}$ & 0,71 ns & $0,44 \mathrm{~ns}$ & $0,17 \mathrm{~ns}$ & $0,13 \mathrm{~ns}$ & $1,84 \mathrm{~ns}$ \\
\hline TXP & 6 & $3,31 * *$ & $1,57 \mathrm{~ns}$ & $1,46 \mathrm{~ns}$ & $2,19 \mathrm{~ns}$ & $1,10 \mathrm{~ns}$ & $1,17 \mathrm{~ns}$ & $0,38 \mathrm{~ns}$ & $0,89 \mathrm{~ns}$ \\
\hline RxTXP & 12 & $1,30 \mathrm{~ns}$ & $1,54 \mathrm{~ns}$ & $0,95 \mathrm{~ns}$ & $0,18 *$ & $2,04 *$ & $1,25 \mathrm{~ns}$ & $1,44 \mathrm{~ns}$ & $1,38 \mathrm{~ns}$ \\
\hline Resíduo & 108 & & & & & & & & \\
\hline CV\% & & 4,18 & 3,77 & 2,39 & 1,26 & 6,48 & 4,43 & 11,82 & 4,37 \\
\hline
\end{tabular}

${ }^{\star,}{ }^{\star \star}$ e ns - Significativo a 1 e $5 \%$ de probabilidade e não significativo; Mic - Índice de Micronaire ( $\left.\mu \mathrm{g} / \mathrm{pol}\right)$; STR - Resistência a ruptura (g/tex); CoMP - comprimento médio (mm); UNIF - Índice de uniformidade de comprimento (\%); IFC - Índice de fibra curtas (\%); ELON - Alongamento à ruptura (\%); CSP - İndice de fiabilidade; MAT - Maturidade; + b - Grau de amarelamento; PDRL - posicionamento do dispositivo para regulagem da quantidade de línter

câmara de descaroçamento e, como as serras estão em rotação, o contato com o algodão depositado na câmara de descaroçamento formará um cilindro de massa de algodão em movimento contrário ao das serras. O descaroçamento ocorrerá pela ação dos dentes das serras na massa do algodão que se enganchará nas fibras e as conduzirá para fora da câmara de descaroçamento. Na etapa seguinte as sementes desprovidas da pluma caem em uma pequena bandeja para serem ensacadas (Figura 5E) e a pluma é conduzida para a parte posterior da máquina, onde se localiza o cilindro de escovas (Figura 5C), que atua junto aos dentes das serras, em sentido inverso ao da rotação e com velocidade bem superior à do cilindro de serra, com a finalidade de retirar a pluma contida nos dentes e impulsioná-la para o condensador (Figura $5 \mathrm{~F})$ que atua como aglutinador da pluma, fazendo com que a mesma saia em forma de manta por meio de rolos.

\section{Avaliação do descaroçador de 20 serras em função da fibra}

Encontra-se, na Tabela 5, o resumo da análise de variância dos dados obtidos para as características tecnológicas das fibras do algodão, em função da rotação, tamanho da amostra e posicionamento do dispositivo para regulagem da quantidade de línter (PDRL).

Em análise dos dados contidos nesta tabela, as características micronaire, resistência a ruptura, índice de uniformidade de comprimento e grau de amarelamento, foram significativas para rotação. Observam-se, também, efeitos significativos para micronaire, comprimento médio de fibra, alongamento à ruptura e índice de fiabilidade, com o fator tamanho da amostra. Entretanto, para o PDRL as características estudadas não foram afetadas significativamente. Para a interação rotação versus tamanho da amostra, as variáveis entre comprimento médio e grau de amarelamento foram significativas e micronaire foi significativa para rotações versus PDRL, tal como a uniformidade de comprimento e micronaire para a interação entre tamanho da amostra versus PDRL.

Os valores médios dos resultados das características de fibra de algodão em função dos fatores: rotação, tamanho da amostra e posicionamento do dispositivo para regulagem da quantidade de línter (PDRL), estão na Tabela 6. Todas as características tecnológicas analisadas foram influenciadas pelas rotações, exceto comprimento médio, índice de fiabilidade e alongamento a ruptura, embora as mesmas não tenham sido afetadas quando beneficiadas pelo descaroçador de 20 serras
A.

B.

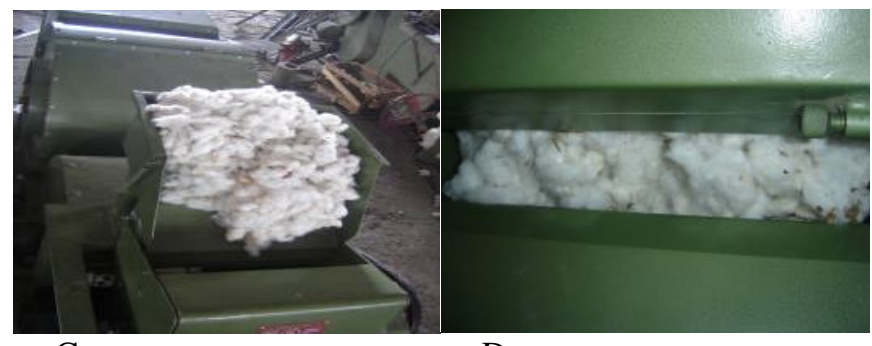

C.

D.

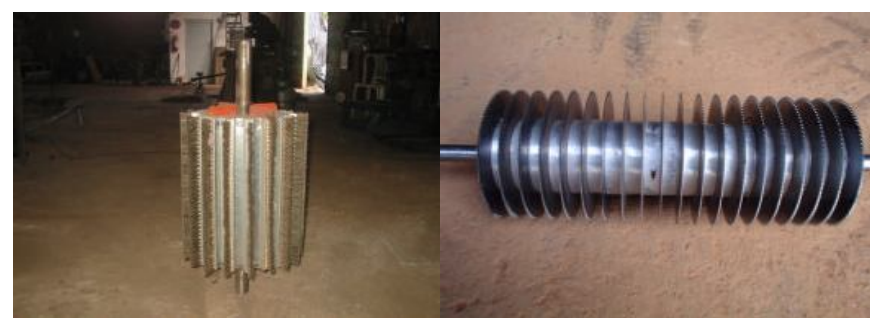

E F.

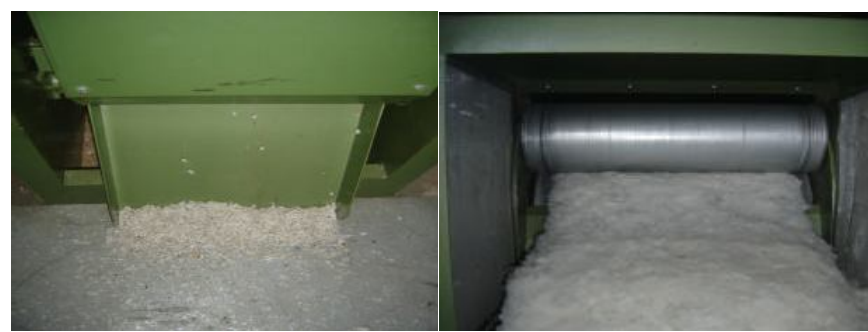

Figura 5. Caixa acumuladora (A); câmara de descaroçamento (B); cilindro de escova (C); cilindro de serras (D); bandeja para recepção das sementes $(E)$ e condensador e rolo (F)

trabalhando a 344 rpm, em relação às exigências estabelecidas pelos padrões de classificação da indústria têxtil nacional (Fonseca \& Santana, 2002).

Essas alterações podem estar relacionadas às variações que ocorrem dentro de cada cultivar em relação às características tecnológicas da fibra que, embora se possam enquadrá-las dentro de uma mesma categoria na qual existe uma faixa de variação, em que o teste estatístico é possível ser avaliado como efeito do beneficiamento, fato que, em parte, encontra apoio nas afirmações de Silva et al. (2002) e Patil \& Patil (2010) ao afirmarem que o processo de beneficiamento não afeta, de forma consistente, essas características. 
Tabela 6. Valores médios das características da fibra de al go dão em função dos fatores rotação, tamanho da amostra, posicionamento do dispositivo para regulagem da quantidade de línter. Campina G rande, PB

\begin{tabular}{|c|c|c|c|c|c|c|c|}
\hline \multirow{2}{*}{ Fatores } & \multicolumn{7}{|c|}{ Variáveis } \\
\hline & MIC & STR & COMP & UNIF & ELON & CSP & $+b$ \\
\hline \multicolumn{8}{|l|}{ a,Rotações } \\
\hline 304 & $3,87 \mathrm{~b}$ & $33,93 a$ & 29,96 a & $82,57 a b$ & $8,65 a$ & 149,22 a & $8,60 a b$ \\
\hline 344 & $3,96 a$ & $33,63 \mathrm{a}$ & 29,83 a & 82,89 a & $8,64 a$ & $150,10 \mathrm{a}$ & $8,69 a$ \\
\hline 429 & $3,85 \mathrm{~b}$ & $32,97 \mathrm{~b}$ & 30,07 a & $82,35 \mathrm{~b}$ & $8,67 a$ & $146,31 \mathrm{a}$ & $8,49 \mathrm{~b}$ \\
\hline \multicolumn{8}{|l|}{ B,T,Amostra } \\
\hline 300 & $3,86 \mathrm{~b}$ & 33,71 a & $30,06 \mathrm{a}$ & $82,72 \mathrm{a}$ & $8,52 \mathrm{~b}$ & $150,61 \mathrm{a}$ & $8,54 a b$ \\
\hline 600 & $3,78 b$ & 33,13 a & 30,31 a & $82,65 a$ & $8,65 a b$ & $149,72 a b$ & $8,47 \mathrm{~b}$ \\
\hline 900 & $3,83 \mathrm{~b}$ & 33,45 a & 30,17 a & $82,55 \mathrm{a}$ & $8,61 a b$ & 149,52 b & $8,65 a b$ \\
\hline 1100 & $4,10 a$ & $33,74 a$ & $29,25 \mathrm{~b}$ & $82,50 a$ & $8,84 a$ & $144,33 \mathrm{~b}$ & $8,73 a$ \\
\hline \multicolumn{8}{|l|}{ c, PDRL } \\
\hline A & $3,92 \mathrm{a}$ & $33,44 a$ & 29,87 a & $82,55 \mathrm{a}$ & $8,64 a$ & $148,02 \mathrm{a}$ & $8,58 \mathrm{a}$ \\
\hline B & $3,90 \mathrm{a}$ & 33,57 a & 29,90 a & 82,62 a & $8,69 a$ & $147,95 a$ & $8,58 \mathrm{a}$ \\
\hline C & $3,87 \mathrm{a}$ & 33,51 a & 30,07 a & $82,65 a$ & $8,63 \mathrm{a}$ & 149,66 a & $84,66 a$ \\
\hline CV\% & 4,18 & 3,77 & 2,39 & 1,26 & 4,43 & 11,82 & 4,37 \\
\hline
\end{tabular}

Nas colunas, médias seguidas da mesma letra, dentro de cada fator, não diferem significativamente entre si pelo teste de Tukey, a $5 \%$ de probabilidade

Mic - índice de micronaire $\left(\mu \mathrm{g} \mathrm{pol}^{-1}\right)$; STR - resistência a ruptura (g/tex); COMP - comprimento médio, mm; UNIF - índice de uniformidade de comprimento (\%); ELON - alongamento a ruptura (\%); CSP - índice de fiabilidade; MAT - maturidade; + b - grau de amarelamento; PDRL - posicionamento do dispositivo para regulagem da quantidade de línter

Apesar de diferença estatística para uniformidade de comprimento entre as rotações, os valores obtidos não foram suficientes para afetar a resistência e a finura da fibra, conforme padrão estabelecido pela BM\&F (1992), em que a uniformidade determinada permaneceu na categoria - uniformidade média.

Com relação ao tamanho da amostra, somente índice de uniformidade de comprimento e resistência à ruptura não foram alterados significativamente (Tabela 6), e a maior amostra (1100 g) foi estatisticamente superior para todas as variáveis, exceto para comprimento médio de fibra e índice de fiabilidade, fato que se deve, provavelmente, à amostra de $1100 \mathrm{~g}$, que permanece, por período maior, em contato com o cilindro de serras promovendo, desta forma, redução do comprimento médio da fibra.

Em referência à micronaire, evidenciam-se flutuações nos valores com tendência de aumento quanto ao tamanho da amostra e que nos valores obtidos se enquadra a fibra desse algodão na categoria fibra fina, utilizada pela indústria têxtil (Fonseca \& Santana, 2002).

As características tecnológicas da fibra não sofreram efeito do posicionamento do dispositivo para regulagem da quantidade de línter (PDRL), não influindo, portanto, na qualidade da fibra, do ponto de vista das exigências da indústria têxtil.

Funk \& Gamble (2009), constataram avaliando a eficiência do descaroçador por serra e cilíndrico sobre propriedades de fibra de algodão colorido que, quando separado por cor, o descaroçador cilíndrico resultou em aumento de $0,7 \mathrm{~mm}$ no comprimento HIV e uma diminuição de 32 a $33 \%$ nos resíduos de fibra. $\mathrm{O}$ descaroçador cilíndrico reduziu a força e melhorou a uniformidade para uma cor e reduziu o teor de fibra curta para ambas as cores. Para os autores, o descaroçador cilíndrico é mais caro que o descaroçamento por serra mas as melhorias nas propriedades de fibra e potenciais aumentos de rendimento, ajudam a compensar o custo adicional; resultado similar foi observado para o algodão branco, por Amijo \& Gillum (2007), que registraram aumento de comprimento da fibra de 29,5 para $30,5 \mathrm{~mm}$, ao compararem descaroçamento por serra e rolo cilíndrico. Esses autores registraram que a uniformidade cresceu de 81 para 82,8 e a força caiu de 27,8 para $27,4 \mathrm{~g} /$ tex, embora sem diferenças estatísticas em relação ao decréscimo da força quando utilizaram descaroçadeira cilíndrica. Queiroga et. al (1994), avaliando a influência do beneficiamento nas características tecnológicas da fibra de algodão herbáceo submetidas aos descaroçadores de serra com as rotações de 400, 550 e 700 rpm em relação ao de rolo com rotação de 350 rpm, constataram que o descaroçador de rolo teve desempenho superior em relação aos descaroçadores de serra para as variáveis de comprimento de fibra; por outro lado, o descaroçador de rolo permitiu a obtenção de fibras pelo menos $1 \mathrm{~mm}$ maior que o descaroçador de serras.

\section{CONCLUSÕES}

1. O descaroçador de 20 serras desenvolvido responde satisfatoriamente ao beneficiamento do algodão com desempenho similar ao das máquinas de 50 e 90 serras para todas as características tecnológicas analisadas da fibra no HVI.

2. A melhor eficiência de trabalho do descaroçador de 20 serras foi para a rotação de $344 \mathrm{rpm}$, com o dispositivo para regulagem de quantidade de línter na posição A e amostra de $600 \mathrm{~g}$.

3. As características tecnológicas do algodão beneficiado no descaroçador de 20 serras se mantiveram dentro do padrão estabelecido pelas normas oficiais de classificação do algodão brasileiro.

\section{LITERATURA CITADA}

Armijo, C. B.; Gillum, M. N. High-speed roller ginning of upland cotton. Applied Engineering in Agriculture, v.3, p.137-143, 2007.

BM\&F - Bolsa de Mercadorias \& Futuros. Resultados de testes de HVI e sua interpretação. São Paulo: BM\&F, 1992. 158p. 
Fonseca, R. G. da; Santana, J. C. F. de. Resultados de ensaio HVI e suas Interpretações (ASTMD-4605). Campina Grande: Embrapa Algodão, 2002. 13p. Circular Técnica, 66

Funk, P. A.; Gamble, G. R. Fiber properties of saw an roller ginned naturally colored cottons. Journal of Cotton Science, v.13, p.166-173, 2009.

Holt, G. A.; Laird, J. W. Initial fiber quality comparisons of the power roll gin stand to three different makes of conventional gin stands. American Society of Agricultural and Biological Engeineers, v.24, p.295-299. 2008.

Holt, G. A.; Laird, J. W. Power roll gin stand technology: Evaluation and optimization of rib rail angle and ginning point modifications on a retrofitted lummus gin stand. American Society of Agricultural and Biological Engineers, v.26, p.209-215, 2010.

Jerônimo, J. F.; Silva, O. R. R. F. da; Almeida, F. de A. C.; Gomes, J. P. G.; Fonseca, R. G. da. Impactos de três descaroçadores sobre a qualidade tecnológica de fibra em dois cultivares de algodão. Revista de Oleaginosas e Fibrosas, v.10, p.969975, 2006.

Koç, E; Demiryürek, O. Theoretical investigation of separator unitis in saw-gin machines. I: Cotton flow rate estimation. Fibres \& Textiles in Eastern Europe, v.13, p.78-83, 2005.

Mangialardi Júnior, G. J.; Anthony, W. S. Field evaluations of air and saw lint cleaning systems. Journal of Cotton Science, v.2, p.53-61, 1998.

Moore, V. P. Development of the saw gin. Department of Agriculture. Cotton Ginners handbook. Washinton: EUA. 1977. p.1- 4. Agriculture Handbook, 503
Paiva, L. E.; Medeiros Filho, S.; Fraga, A. C. Beneficiamento de sementes de milho colhidas mecanicamente em espigas: Efeitos sobre danos mecânicos e qualidade fisiológica. Ciência Agrotécnica, v.24, p.846-856, 2000.

Patil, P. G.; Patil, V. Development of prototype double roller gin with improved power transmission and its performance evaluation. Journal of Engineered Fibers and Fabrics, v.5, p.20-25, 2010.

Queiroga, V. de P.; Barros, M. A. L.; Vale, L. V.; Matos, V. P. Influência da colheita, armazenamento temporário e beneficiamento nos caracteres tecnológicos do algodão herbáceo. Revista Ceres, v.41, p.337- 357, 1994.

Silva, O. R. R. F. da. Miniusinas de 20 e 50 serras. In: Congresso Brasileiro de Algodão, 6, Uberlândia. Anais... Uberlândia: UFMG 2007. CD-Rom

Silva, O. R. R. F. da.; Santana, J. C. F de; Cartaxo, W. V.; Luz, M. J. S. da; Santos, J. W. dos. Influência do descaroçamento nas características tecnológica da fibra do algodão analisado pelo HVI (high volume instruments) e pelo AFIS (advanced fiber information system). Revista Brasileira de Oleaginosas e Fibrosas, v.6, p.497-501, 2002.

Silva, O. R. R. F. da; Sofiatti, V.; Santana, J. C. F. de; Wanderley, M. J. R.; Santos, J. W. dos. Impacto do beneficiamento sobre o número de neps e quantidade de impurezas da fibra do algodão. Revista Brasileira de Engenharia Agrícola e Ambiental, v.14, p.107-112, 2010.

Souza, D. C.; Albuquerque, M. C. de F.; Zorato, M. de F.; Carvalho, D. do C. Análise de danos mecânicos e qualidade de sementes de algodoeiro. Revista Brasileira de Sementes, v.31, p.123-131, 2009. 